\title{
Determination and climatology of the planetary boundary layer height above the Swiss plateau by in situ and remote sensing measurements as well as by the COSMO-2 model
}

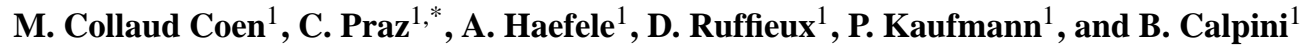 \\ ${ }^{1}$ Federal Office of Meteorology and Climatology, MeteoSwiss, 1530 Payerne/8044 Zurich, Switzerland \\ *now at: ESA Advanced Concept Team, ESTEC, Keplerlaan 1, 2201 AZ Noordwijk, the Netherlands
}

Correspondence to: M Collaud Coen (martine.collaudcoen@meteoswiss.ch)

Received: 17 April 2014 - Published in Atmos. Chem. Phys. Discuss.: 12 June 2014

Revised: 23 October 2014 - Accepted: 10 November 2014 - Published: 11 December 2014

\begin{abstract}
The planetary boundary layer (PBL) height is a key parameter in air quality control and pollutant dispersion. The PBL height cannot, however, be directly measured, and its estimation relies on the analysis of the vertical profiles of the temperature, turbulence or the atmospheric composition. An operational PBL height detection method including several remote sensing instruments (wind profiler, Raman lidar, microwave radiometer) and several algorithms (Parcel and bulk Richardson number methods, surface-based temperature inversion, aerosol or humidity gradient analysis) was developed and tested with 1 year of measurements, which allows the methods to be validated against radio sounding measurements. The microwave radiometer provides convective boundary layer heights in good agreement with the radio sounding (RS) (median bias $<25 \mathrm{~m}, R^{2}>0.70$ ) and allows the analysis of the diurnal variation of the PBL height due to its high temporal resolution. The Raman lidar also leads to a good agreement with RS, whereas the wind profiler yields some more dispersed results mostly due to false attribution problems. A comparison with the numerical weather prediction model COSMO-2 has shown a general overestimation of the model PBL height by some hundreds to thousand meters. Finally the seasonal cycles of the daytime and nighttime PBL heights are discussed for each instrument and each detection algorithm for two stations on the Swiss plateau.
\end{abstract}

\section{Introduction}

The height of the planetary (or atmospheric) boundary layer (PBL) is a key parameter for air quality analysis, pollutants dispersion and quantification of pollutant emissions and sources. The PBL controls the interactions of the atmosphere with the oceans and land and determines the air volume available for the dispersion of all atmospheric constituents, including anthropogenic pollution and water vapor, emitted at the Earth's surface. Hence the PBL contributes to the assessment of the pollutant concentration near the surface and the PBL height is thus a key parameter of all air pollution models. Despite its critical importance, the PBL cannot be directly measured but has to be estimated by upper-air instruments.

The COST (European Cooperation in Science and Technology) action 710 (Harmonisation of the pre-processing of meteorological data for atmospheric dispersion models) defined the daytime PBL height as "the height of the layer adjacent to the ground over which pollutants or any constituents emitted within this layer or entrained into it become vertically dispersed by convection or mechanical turbulence within a time scale of about an hour" (COST action 710 Final report, 1998). The PBL height can consequently be estimated by the measurement of mechanical turbulence, of the temperature enabling convection or of the concentration of PBL constituents. These detection methods are based on various atmospheric parameters, various measuring instruments and different analysis algorithms, leading to several PBL height estimations that are not always consistent with each other. The first measurements of the PBL were performed us- 


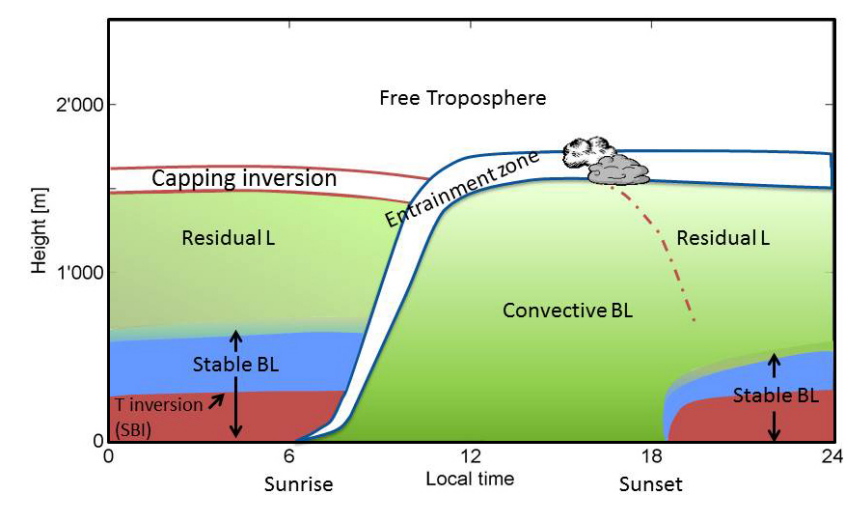

Figure 1. Diurnal cycle of the PBL height over land for a clear convective day (adapted from Stull, 1988).

ing surface and tower observations of vertical wind profiles and deeply investigating wind turbulence. The intense development of remote sensing instruments nowadays offers a wide field of vertical profiles up to several kilometers, which allows PBL height detection from the surface with high temporal resolution.

The PBL experiences a marked diurnal cycle that depends on both the synoptic and local weather conditions. In the case of fair weather days, the PBL height has a well-defined structure and diurnal cycle (Fig. 1), leading to the development of a convective boundary layer (CBL), also called a mixing layer, during the day and of a stable boundary layer (SBL), which is capped by a residual layer (RL) during the night (Stull, 1988). In the case of cloudy or rainy conditions and in the case of advective weather conditions, free convection is no longer driven primarily by solar heating, but by ground thermal inertia, cold air advection, forced mechanical convection and/or cloud top radiative cooling. In those cloudy cases, the CBL development remains weaker than in the case of clear sky conditions, with slower growth and lower maximum height. The boundary layer is said to be neutral if the buoyancy is near zero; these neutral cases are found for overcast conditions with strong winds but little temperature differences between the air and the ground. Neutral conditions are frequently met in the RL but rarely near the surface. The PBL development under clear sky conditions (i.e., more than $50 \%$ of solar radiation during the CBL development) that leads to strong convection driven principally by solar heating will be called CBL. For all "no clear-sky" cases with partial or total cloud coverage but without precipitation, the PBL will be called cloudy-CBL.

While the definition and the measurement of the CBL, the neutral boundary layer (NBL) and the cloudy-CBL are well established, the nocturnal SBL presents a more complicated internal structure. It is comprised of a stable layer caused by radiative cooling from the ground, which gradually merges into a neutral layer called the RL (Stull, 1988; Salmond and McKendry, 2005; Mahrt et al., 1998). The stable layer can be characterized by a surface-based temperature inversion (SBI), and its top can be estimated by the height at which the gradient of the potential temperature $(\theta)$ equals zero. Smallscale and short-term turbulence can occur within this stable layer. The RL height is the top of the neutral layer and the beginning of the stable free troposphere. The pollutants emitted from the surface during the night are trapped into the SBI, whereas the pollutants released on past days tend to stay in the RL.

Contrary to radio sounding (RS), launched usually only twice a day, continuous remote sensing measurements allow the determination of the diurnal cycle of the different layers constituting the PBL. The use of remote sensing instrumentation to detect the PBL height was recently summarized by Emeis (2009). Recent studies compared several detection methods or retrieval techniques (Bianco and Wilczac, 2002; Seidel et al., 2010; Beyrich and Leps, 2012; Haeffelin et al., 2012; Summa et al., 2013), remote sensing with RS measurements (Baars et al., 2008, Liu and Liang 2010, Granados-Muñoz et al., 2012; Milroy et al., 2012; Sawyer and Li, 2013; Cimini et al., 2013) and/or several remote sensing instruments (Wang et al., 2012; Zahng et al., 2012). In most of these studies, good correlations are found in the case of strong or weak convective weather conditions with differences of 100-300 m between the various instruments and/or methods. Non-convective weather conditions corresponding in most of the cases to cloudy and rainy conditions lead to much greater discrepancies in the PBL height estimations. In these cases, the difference becomes even greater if the methods/instruments are designed to detect various types of PBL such as CBL, NBL or RL. If temperature profiles are measured, bulk Richardson number (bR) or Parcel (PM) methods are usually considered as the most relevant methods for daytime PBL height detection. Some studies also compared measurements with models predictions (Baars et al., 2008; Seidel et al., 2012; Ketterer et al., 2014), the results depending on both the model and the measurement type.

Climatologies of PBL height have been performed on time series from 1 to 25 years long in Europe and the United States (Baars et al., 2008; Schmid and Niyogy, 2012; Beyrich and Leps, 2012; Granados-Muñoz et al., 2012; Sawyer and Li, 2013) and over continents (Seidel et al., 2010, 2012). For continental stations, a clear CBL seasonal cycle is usually found with a maximum height reaching 1000 to $2000 \mathrm{~m}$ above ground level (a.g.l.) in summer and and a minimum height reaching 500 to $1200 \mathrm{~m}$ a.g.l in winter. The seasonal cycle of the nocturnal SBL was only addressed on the basis of temperature ( $T$ ) profiles from RS measurements (Seidel et al., 2010, 2012; Beyrich and Leps, 2012). Both papers found a minimum height in summer and a maximum height in winter, which was attributed to greater wind speeds and consequently stronger mechanical turbulence during winter. Few of the PBL height detections run operationally, meaning that they run as fully automatic systems delivering routine PBL 
Table 1. List of abbreviations.

\begin{tabular}{|c|c|}
\hline \multicolumn{2}{|c|}{ Atmospheric layers } \\
\hline $\begin{array}{l}\text { CBL } \\
\text { cloudy-CBL }\end{array}$ & $\begin{array}{l}\text { convective boundary layer } \\
\text { CBL for overcast conditions but without } \\
\text { precipitations }\end{array}$ \\
\hline NBL & neutral boundary layer \\
\hline PBL & planetary boundary layer \\
\hline RL & residual layer \\
\hline SBL & stable boundary layer \\
\hline \multicolumn{2}{|l|}{ Instruments } \\
\hline lidar & Raman lidar \\
\hline MWR & microwave radiometer \\
\hline RS & radio sounding \\
\hline WP & wind profiler \\
\hline \multicolumn{2}{|l|}{ Methods } \\
\hline APCADA & $\begin{array}{l}\text { Automatic Partial Cloud Amount Detection } \\
\text { Algorithm }\end{array}$ \\
\hline ASR & Aerosol Scattering Ratio \\
\hline bR & bulk Richardson number method \\
\hline COSMO-2 & COnsortium for Small-scale MOdeling \\
\hline $\mathrm{PM}$ & Parcel Method \\
\hline SBI & Surface-based Temperature Inversion \\
\hline SBLpT & $\begin{array}{l}\text { Stable Boundary Layer detected by potential } \\
\text { Temperature }\end{array}$ \\
\hline SNR & Signal-to-noise ratio \\
\hline \multicolumn{2}{|c|}{ Measuring sites } \\
\hline PAY & Payerne \\
\hline SHA & Schaffhausen \\
\hline
\end{tabular}

estimation in realtime. Some authors specify that a visual inspection is necessary to increase the results reliability.

In this study, an operational system for PBL height detection has been developed based on the analysis of vertical atmospheric profiles of $T$, wind turbulence and atmospheric constituents, which are measured by three different remote sensing techniques, radar wind profiler (WP), microwave radiometer (MWR) and lidar, as well as by radio sounding. One year (2012) of measurements was used to compare these independent PBL height determinations against a reference method, here taken as the RS or MWR PBL heights derived from the PM. The PBL heights computed by the COSMO-2 model (numerical weather prediction model of the Consortium for Small Scale Modeling; see www.cosmo-model.org) were also compared to the instrumental PBL height determination. A 2-year climatology of the CBL, the cloudy-CBL and the different layers constituting the nocturnal SBL was moreover computed for Payerne (PAY) and Schaffhausen (SHA) both located on the Swiss plateau.

This paper gives a description of the instruments and the methods used to derive the PBL heights, some examples of PBL height estimations, the inter-comparison and validation of the experimental methods, a comparison with COSMO-2 model and a 2-year climatology. Recommendations about the most comprehensive set of instruments for an operational detection of the PBL diurnal cycle are given in the conclusion. Abbreviations for the sites, instruments and methods as well as for the different PBL layers are summarized in Table 1. Throughout the paper, the various PBL detections are named by the measuring instrument and the applied method, RS/PM being for example given for Parcel method (PM) applied to RS measurements. If not specified, elevations or heights are given as above ground level (a.g.l.) and time as LT (equal to $\mathrm{UTC}+1)$.

\section{Experimental}

\subsection{Site and instrumentation}

For this study, a 2-year (2012-2013) data set from the two upper-air remote sensing sites Payerne $(491 \mathrm{~m}$ a.s.l., $\left.46.799^{\circ} \mathrm{N}, 6.932^{\circ} \mathrm{E}\right)$ and Schaffhausen $(437 \mathrm{~m}$ a.s.l., $47.672^{\circ} \mathrm{N}, 8.604^{\circ} \mathrm{E}$ ) of the $\mathrm{CN}-$ Met (Centrales Nucléaires et METéorologie) measurement network (Calpini et al., 2011) were used. Both sites are located on the Swiss plateau in rural areas, each in proximity of a small city. Both stations include a WP, a MWR and a SwissMetNet surface station. A ceilometer and a Raman lidar were also available at PAY, as well as RS measurements twice a day.

The WPs are Degreane PCL1300 (Degreane Horizon, 2006) with five antennas operating at $1290 \mathrm{MHz}$ $(\lambda=23.3 \mathrm{~cm})$ alternatingly in low and high mode covering altitudes from 0.1 to $3 \mathrm{~km}$ and 0.3 to $8 \mathrm{~km}$, respectively. For this study, only the low mode has been used with a vertical resolution of $150 \mathrm{~m}$ and the first level at $105 \mathrm{~m}$. The wind profiler measures the clear air radar echo generated by inhomogeneities in the refractive index due to atmospheric turbulent structures that are assumed to travel with the background wind. The vertical profile of horizontal and vertical wind is derived from the radial velocities along each direction. The effective time resolution is $40 \mathrm{~min}$ for one vertical profile and consists of a moving average over $10 \mathrm{~min}$ profiles. This temporal resolution is required to obtain a sufficient quality of the wind measurements under all weather conditions. A multipeak picking procedure (MPP) is used to identify the atmospheric signal in the radar spectra and the signal-to-noise ratio (SNR) is then calculated from the five SNR values corresponding to the five antenna directions by taking the minimum SNR. This procedure minimizes high SNR values generated by hard, non-atmospheric targets. Both wind and SNR data undergo a quality check and their availability depends on the atmospheric conditions. The first levels of measurements up to $200-400 \mathrm{~m}$ are often automatically invalidated because they suffer from internal and environmental perturbations. 
The MWR is a passive remote sensing instrument that measures electromagnetic radiation emitted from the atmosphere in the microwave band. From the measured radiation spectrum, the atmospheric $T$ profile between 0 and $5 \mathrm{~km}$ is retrieved. The MWRs employed in this study are TEMPRO radiometers manufactured by Radiometer Physics $\mathrm{GMbH}$ (RPG; 2011) with seven channels between 51 and $58 \mathrm{GHz}$ for $T$ profiling. The radiometer alternates between elevation scanning (six elevations between 5 and $90^{\circ}$ ) and zenith observations. Statistical regressions models are used to convert the radiation measurements from the elevation scan and from the zenith observations in two temperature profile covering $0-2 \mathrm{~km}$ and $0-5 \mathrm{~km}$, respectively. The two temperature profiles are merged into one single $T$ profile using the profile derived from the elevation scan and the upper part $(2-5 \mathrm{~km})$ of the profile derived from the zenith observations. The vertical resolution decreases with altitude, from $50 \mathrm{~m}$ for $z<1200 \mathrm{~m}$ to $200 \mathrm{~m}$ at $3000 \mathrm{~m}$ according to the manufacturer. These values are however derived from the averaging kernels, which depend slightly on the atmospheric conditions. Hence, elevated $T$ inversions (above approximately $1500 \mathrm{~m}$ ) cannot be resolved by the MWR. The time resolution is set to one profile every $10 \mathrm{~min}$.

The PAY aerological station is equipped with a fully automated and operational Raman lidar designed for continuous measurements of tropospheric water vapor, aerosols and temperature in dry conditions (Dinoev et al., 2013). The transmitter is a Nd:YAG-laser emitting UV pulses $(300 \mathrm{~mJ}$ per pulse, $30 \mathrm{~Hz}$ repetition rate) at a wavelength of $355 \mathrm{~nm}$. The receiver consists of four telescopes of $0.3 \mathrm{~m}$ diameter each, which are fiber coupled to the polychromator, which spectrally separates the backscattered light. Separate photomultipliers simultaneously detect vibrational Raman scatter from nitrogen $(387 \mathrm{~nm})$ and water vapor $(407 \mathrm{~nm})$ signals, two portions of the pure rotational Raman spectrum and the elastic backscatter. The aerosol scattering ratio is then derived from the sum of the rotational Raman signals and the elastic signal (Dinoev et al., 2010). The maximum range varies from $4000 \mathrm{~m}$ during the day up to $8000 \mathrm{~m}$ during the night for the water vapor measurements and from $7000 \mathrm{~m}$ (day) to $12000 \mathrm{~m}$ (night) for aerosol backscatter ratio measurements. The first range level is located at $110 \mathrm{~m}$. The vertical resolution is dynamically adapted to the measurement conditions, varying from $30 \mathrm{~m}$ near the surface to a maximum of $300 \mathrm{~m}$ in the upper troposphere. However, the signal-to-noise ratio is very high in the boundary layer and the vertical resolution remains constant $(30 \mathrm{~m})$. The effective time resolution of profiles is $30 \mathrm{~min}$. No measurements are possible during precipitation and in the presence of low clouds, i.e., the lidar powers down if the clouds are below $900 \mathrm{~m}$ or there is precipitation and powers up as soon as the cloud base rises above $2000 \mathrm{~m}$ and there is no precipitation.

A ceilometer (CBME80 from Eliasson) measuring at $\lambda=905 \mathrm{~nm}$ with a time resolution of a few seconds is interfaced to the lidar system to provide independent cloud infor- mation. This model was not configured to record backscatter profiles but only to provide the height of the cloud bases detected by a strong gradient in the backscattered signal.

In addition to the remote sensing instruments, the Payerne station performs routine RS providing pressure $(p), T$, humidity and wind speed and direction profiles up to $32 \mathrm{~km}$. Meteolabor SRS 400 C34 radiosondes are launched twice a day at 00:00 and 12:00 LT. The horizontal displacement of the sonde can reach up to $200 \mathrm{~km}$. However, only the first vertical $3500 \mathrm{~m}$ corresponding to approximately $12 \mathrm{~min}$ of rise are used to determine the PBL height, allowing one to neglect the RS horizontal displacement. RS has a constant height resolution of 5 to $6 \mathrm{~m}$ corresponding to a $1 \mathrm{~s}$ time resolution.

The COSMO-2 model (http://www.cosmo-model.org) was used in assimilation mode. It has a horizontal grid spacing of $2.2 \mathrm{~km}$ and a total of 60 vertical levels, of which 15 lie within the first $500 \mathrm{~m}$. The time step is $20 \mathrm{~s}$ and data are written out every $1 \mathrm{~h}$. The bulk Richardson number method is used to estimate the boundary layer height in the model (see Sect. 2.2.1).

The SwissMetNet meteorological surface network provides surface $T$, humidity, $p$, wind direction and speed as well as sunshine duration and precipitation every $10 \mathrm{~min}$. As recommended by the standard procedures of the World Meteorological Organization (WMO), the wind components are measured at $10 \mathrm{~m}$ and all the other parameters at $2 \mathrm{~m}$. In addition, the PAY station is equipped with a sonic anemometer on a $10 \mathrm{~m}$ mast measuring several parameters related to turbulence, including the sensible heat flux, which characterizes the thermal energy exchanges. The sensitive heat flux is then used to estimate the intensity of convective forcing.

The cloud cover is detected by an automatic partial cloud amount detection algorithm (APCADA) that estimates in realtime the sky cloud cover from surface-based measurements of long-wave downward radiation, $T$ and humidity (Dürr and Philipona, 2004). APCADA does not take into account cirrus clouds.

Measurements from both the MWR and lidar are necessary to calculate the virtual potential temperature $\left(\theta_{v}\right)$, and they are combined with WP data to calculate the bulk Richardson number (see Sect. 2.2.1). These three instruments have however different vertical levels and time constants. For these cases, a vertical scale (35 levels of $100 \mathrm{~m}$ between 0 and $3500 \mathrm{~m}$ ) is set, and the mean of the parameters in each level are used. Despite the rather long integration times in the case of the wind profiler and lidar, all measurements have been assumed to be instantaneous. These different time granularities are sometimes manifested by a time shift of the CBL growth measured by MWR/PM and WP/SNR or lidar/ASR. 
a)

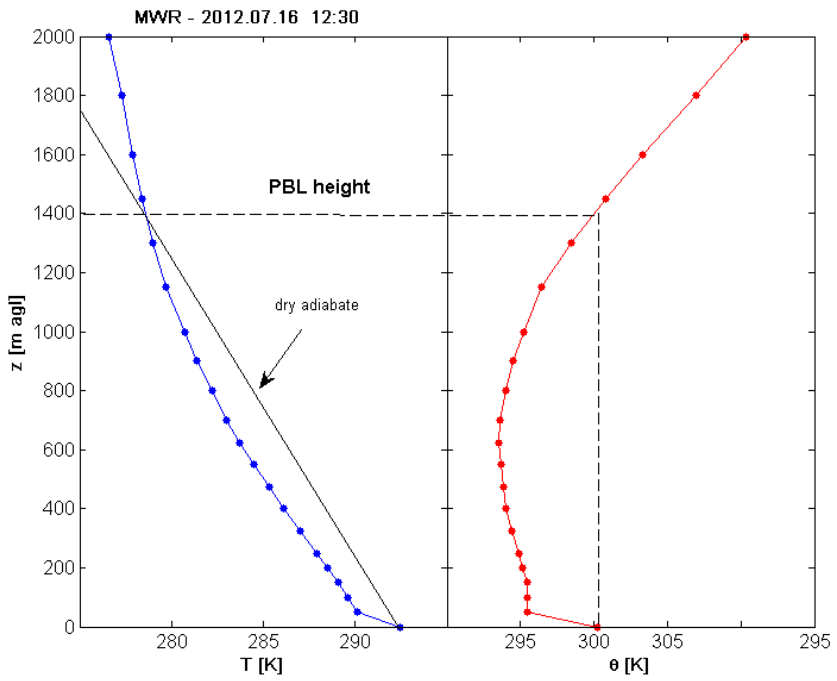

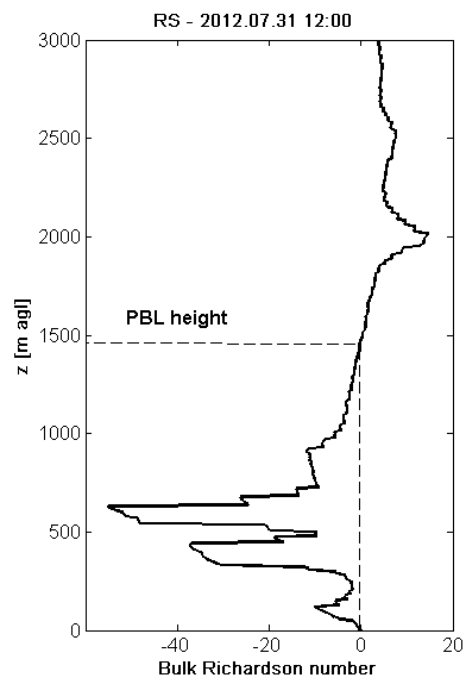

Figure 2. PBL detection methods based on $T$ profiles: (a) parcel method applied to MWR $T$ and $\theta$ profiles and (b) bulk Richardson number method applied to the RS $\theta$ profile. Both profiles were measured at about 12:00 in convective conditions.

\subsection{Methods employed to estimate the PBL height}

\subsubsection{Methods based on $T$ profiles}

The Parcel method (Holzworth, 1964; Fisher et al., 1998) defines the PBL height as the elevation to which an air parcel with ambient surface $T$ can rise adiabatically from the ground by convection. As depicted in Fig. 2, the PBL height is set to the altitude $z$ where the $T$ profile crosses the dry adiabatic or where the potential temperature $\theta(z)$ is equal to the surface $\theta\left(z_{0}\right)$. The PM needs only the $T$ profile and a precise surface $T$ measurement. To apply the PM, the condition $\theta\left(z_{1}\right)<\theta\left(z_{0}\right)$, with $z_{1}>z_{0}$, corresponding to unstable $\theta$ vertical profile, has to be fulfilled. No excess $T$ has been added to the surface $T$. The PM was applied to RS and MWR $\theta$ profiles to detect daytime PBL in the case of weak or strong convective conditions (CBL and cloudy-CBL).

The bulk Richardson number $\left(R i_{\mathrm{b}}\right)$ is a dimensionless parameter combining the potential energy and the vertical wind shear. It corresponds to the ratio of convective and wind shear produced turbulence and is widely used in turbulence characterization. In order to be consistent with the $R i_{\mathrm{b}}$ used in the COSMO-2/bR model (Szintai, 2010), the following formulation was applied:

$R i_{\mathrm{b}}=\frac{g z\left(\theta(z)-\theta\left(z_{0}\right)\right)}{\bar{\theta}\left(U^{2}(z)+V^{2}(z)\right)}$,

where $z$ is the height $\left(z>z_{0}\right), U$ and $V$ the two horizontal wind velocity components, $g$ the Earth gravitational constant and $\bar{\theta}$ the mean $\theta$ between $z_{0}$ and $z$. The PBL height corresponds to the first elevation $z$ with $R i_{\mathrm{b}}$ greater than a critical threshold taken as 0.22 or 0.33 in the case of unstable (day) or stable (night) conditions, respectively (Fisher et al.,
1998; Jericevic and Grisogono, 2006; Szintai, 2010). In most cases, the exact threshold value has only a small impact on the PBL height due to the large slope of $R i_{\mathrm{b}}$ in this interval (see for ex. Fig. 2b). PBL height detected by bR is by definition higher than PBL height detected by PM, because both methods are identical if the threshold value is set to 0 involving $\theta(z)=\theta\left(z_{0}\right)$. The WP wind velocities were used to calculate the $R i_{\mathrm{b}}$ from the MWR $T$ profile. The bR method was applied to daily RS and MWR $\theta$ and COSMO-2 $\theta_{\mathrm{v}}$ profiles for CBL, cloudy-CBL and SBL detection. During night, the $R i_{\mathrm{b}}$ number is sometimes greater than the threshold already at the ground level due to a stable $\theta$ profile near ground impeding any PBL detection. Moreover, the invalidation of the first levels of the wind profiler data caused by internal and environmental perturbations also restrict the detection of low PBL height $(<200-400 \mathrm{~m})$ by the bR method.

For both PM and bR methods, the surface $T$ has a large impact on the determined PBL height, and hence it is crucial to take a representative measurement that is not biased by micrometeorological effects. The surface $T$ was therefore taken from the meteorological surface network at $2 \mathrm{~m}$. If the $T$ profile was measured by the MWR and the PBL height is found between two measured levels, a linear interpolation between the two measured $\theta$ is applied to determine the PBL height. Uncertainties in PBL height for both methods were calculated by varying the surface $T$ by $\pm 0.5^{\circ}$ and were found to be on the order of \pm 50 to $150 \mathrm{~m}$ for the PBL maximum height reached in the early afternoon. Far larger PBL heights uncertainties up to $500 \mathrm{~m}$ were found just before sunset, when the vertical heat flux become negative. For RS, $\theta$ and $\theta_{\mathrm{v}}$ were calculated using $p$ and relative humidity (RH) provided by RS measurements, whereas for MWR, RH was provided by 


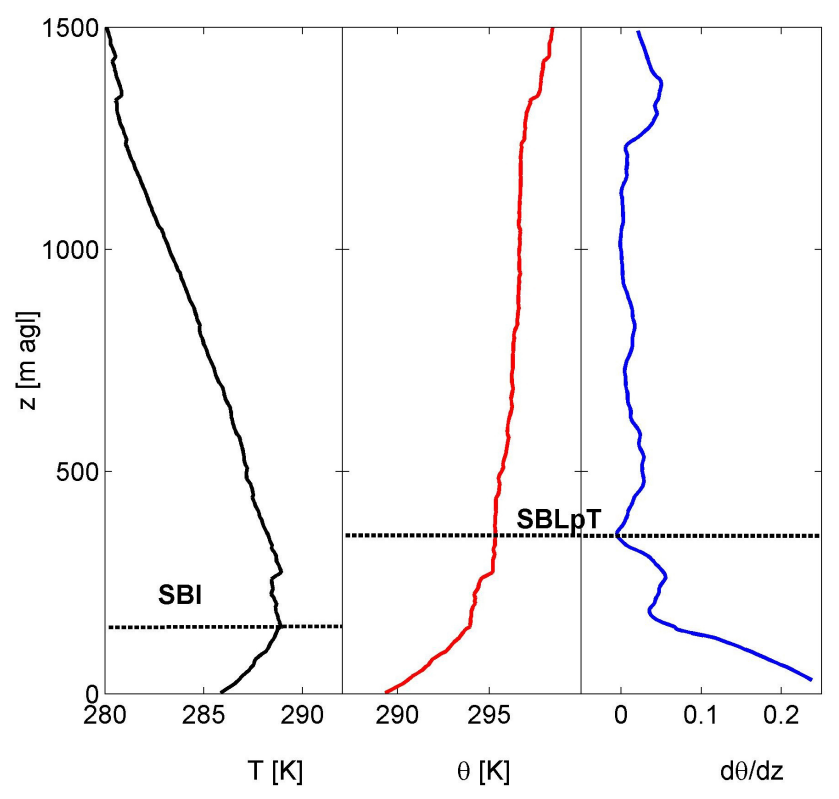

Figure 3. Detection of the SBL from RS $T$ profile of 17/07/2012: (a) the surface-based temperature inversion (SBI) determined by the first $T$ decrease as a function of altitude, (b) the top of the stable layer (SBLpT) detected by the stability of $\theta$ profile or by the vanishing $T$ gradient.

lidar and $p$ was calculated from the MWR $T$ profile by using the ideal gas equation and assuming hydrostatic equilibrium:

$p(z, T)=p_{o} \cdot \exp \left(-\int_{z_{0}}^{z} \frac{M_{\mathrm{a}} g}{R T\left(z^{\prime}\right)} \mathrm{d} z^{\prime},\right)$

where $M_{\mathrm{a}}$ is the mass of the air, $R$ the specific gas constant and $p_{0}$ is measured at $2 \mathrm{~m}$ from the meteorological surface network.

The nocturnal SBL can only be detected by the $T$ profiles measured by RS and MWR, since wind turbulence, aerosol and humidity profiles retrieve the RL height during the night. The SBI is defined as the height of the surface-based $T$ inversion, where $T$ first decreases with elevation $(\mathrm{d} T / \mathrm{d} z=0)$ as depicted in Fig. 3a (Bradley et al., 1993; Stull, 1988). A surface-based $T$ inversion is a clear indicator of a stable boundary layer that can be defined as a SBL height (Seidel et al., 2010). The SBL top can also be defined as the transition between the stable surface layer and the neutral residual layer (Stull, 1988). This height is detected by a vanishing $\theta$ gradient $(\mathrm{d} \theta / \mathrm{d} z=0)$, which will be called SBLpT (Fig. 3b and c) in this paper. SBLpT is by definition higher than SBI since the $\theta$ gradient is still positive at the height of the surfacebased $T$ inversion and does not correspond to the top of the stable layer.

\subsubsection{Method based on wind turbulence profiles}

The radar echo measured by the WP is generated by inhomogeneities in the refractive index, which are characterized by the structure constant $C_{\mathrm{n}}^{2}$. It can be shown that the rangecorrected SNR is proportional to $C_{\mathrm{n}}^{2}$, which has a maximum at the top of the capping inversion, which marks the PBL top (White et al., 1991; Angevine et al., 1994, and references therein). Therefore, a peak in the SNR profile can be associated with the PBL height under convective conditions. However, turbulence as well as humidity and $T$ gradients associated with clouds and other dynamical processes can generate high SNR values, which do not correspond to the PBL height, leading to an attribution problem. To get rid of part of the false PBL height attribution, a time continuity algorithm was applied: the $k$ SNR peaks $\left(s_{k, i}\right)$ at time $i$ with local maximum greater than $75 \%$ of the absolute maximum was weighted by a Gaussian function $g\left(s_{\max , i-1}, \sigma\right)$ with mean equals to the PBL height of the former time step $i-1$ and standard deviation $\sigma$ depending on the time of the day. At sunrise, the Gaussian mean (PBL height) is set to $0 \mathrm{~m}$ a.g.l. and $\sigma$ to $3000 \mathrm{~m}$, that is, three time higher than during the afternoon. The PBL height is then attributed to the maximum of the weighted SNR peak $S_{\max , i}=\max \left(s_{k, i} \times g\left(s_{\max , i-1}, \sigma\right)\right)$. The uncertainty of this method is considered equal to the full width at half maximum (FWHM) of the selected SNR peak after subtraction of the noise floor and is on the order of 100 to $500 \mathrm{~m}$. PBL detection algorithms involving first and second derivatives of the SNR peak were tested but have shown a lower consistency with respect to the other PBL height detection methods in addition to a higher rate of false detections. This WP/SNR method was used to detect the CBL during the day and the RL during the night, but cannot be used in the case of precipitation since the precipitation velocity is measured in that case.

\subsubsection{Method based on concentration profiles}

The aerosol scattering ratio (ASR) is the ratio between the total and the molecular backscatter coefficients. Since the PBL top is characterized by a sharp decrease in concentration of all pollutants, the absolute minima in the vertical gradient of the lidar/ASR and of the RS/RH profiles can be associated with the CBL height during day and to the RL during night. A continuity algorithm similar to the WP/SNR method (see Sect. 2.2.2) was applied, with the modified condition that the local minimum has to be lower than $10 \%$ of the absolute minimum. According to the WP/SNR method, the uncertainty is considered equal to the FWHM of the selected peak in the lidar/ASR gradient profile and is on the order of $100-250 \mathrm{~m}$. 


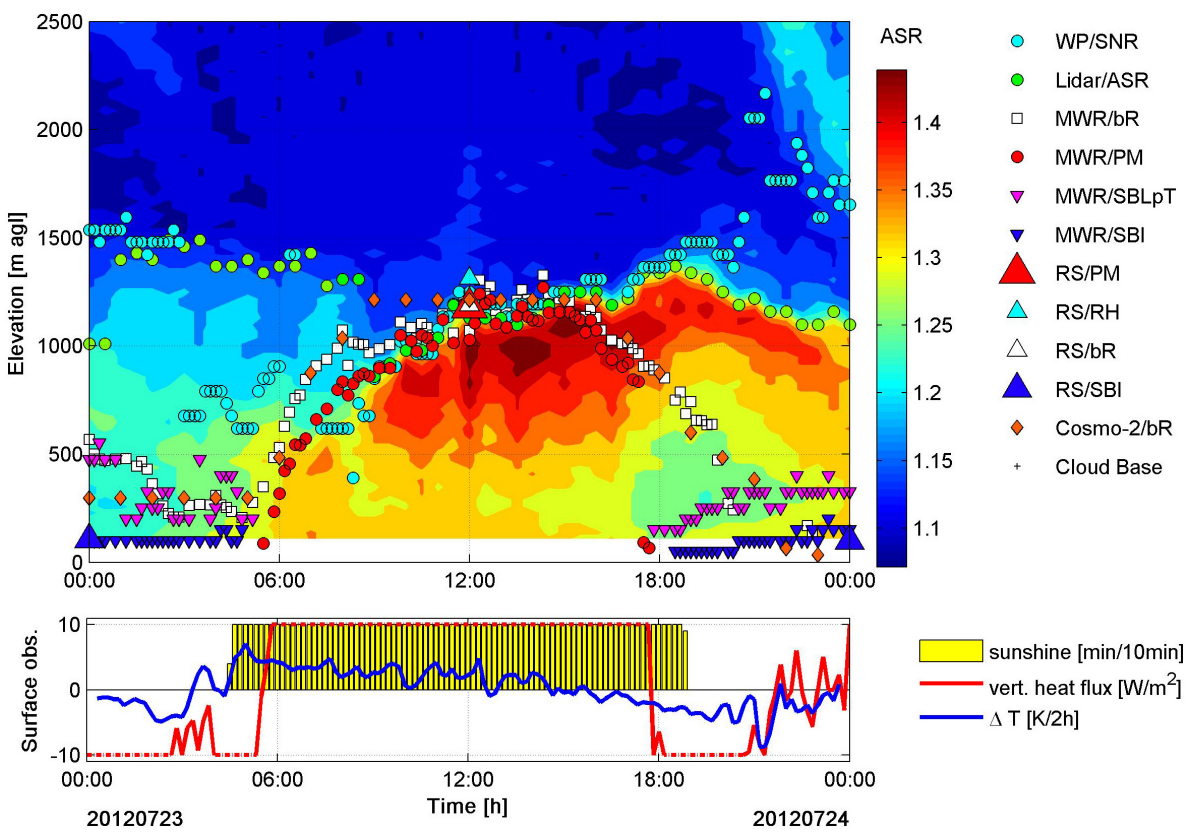

Figure 4. Upper panel: automatic detection of PBL height from all remote sensing instruments, RS and COSMO-2 model for a convective day in summer 2012 at PAY; the background signal corresponds to the lidar/ASR. Lower panel: sunshine duration, vertical heat flux and temporal gradient of surface $T$. Vertical heat flux greater than 10 or lower than $-10 \mathrm{~W} \mathrm{~m}^{-2}$ are limited to \pm 10 with a dashed line.

\section{Results and discussion}

\subsection{Comparison of PBL height determined from potential and virtual potential temperature.}

Both the PM and bR methods can be applied not only to $\theta$ but also to $\theta_{\mathrm{v}}$, where using $\theta_{\mathrm{v}}$ also corrects for air moisture, water vapor being lighter than dry air. The humidity profile of lidar was taken to calculate $\theta_{\mathrm{v}}$ from MWR $T$ profile, restricting the data availability to cloud- and precipitation-free cases. A comparison of PBL height detected by both $\theta$ and $\theta_{\mathrm{v}}$ was performed for 35 convective days (from 12:00 to 15:00) taken between February and September 2012 (Table 2). The PBL heights computed from $\theta_{\mathrm{v}}$ are slightly greater (3-8\%) than those computed from $\theta$. This positive difference can be attributed to the effect of moisture that lightens the air and allows it to convectively rise to a higher altitude. The agreement is however good, resulting in coefficients of determination of at least 0.95 and median bias smaller than $120 \mathrm{~m}$ in all cases. Considering these small differences and the greater $\theta$ availability, the RS and MWR potential temperatures $\theta$ were used for this study.

\subsection{PBL height operational measurement}

The operational procedure calculates the PBL heights each hour. Examples of the resulting plots are presented in Figs. 4 and 5. All PBL heights from the various instruments and methods are plotted on the lidar/ASR (Fig. 4) or on the WP/SNR (Fig. 5) in the upper panel, whereas the vertical heat flux, the sunshine duration and the temporal gradient of the surface $T$ are plotted in the lower panel.

The first example of a clear CBL height diurnal cycle (Fig. 4) was measured at PAY during a clear-sky convective day on the 23 July 2012, where all principal PBL features of Fig. 1 were measured:

- The layered structure of the nocturnal PBL between midnight and the sunrise: (1) the SBI is detected by both RS (dark blue triangles) and MWR (reversed dark blue triangles) at about $100 \mathrm{~m}$, (2) the SBL detected by $\mathrm{MWR} / \mathrm{bR}$ (white squares) and the top of the stable layer detected by the MWR/SBLpT (magenta triangles) peak both at the same altitude of 500 m until 03:00 and decreases to about $200 \mathrm{~m}$ thereafter, (3) the SBL detected by the COSMO- $2 / \mathrm{bR}$ (orange diamonds) stays constant at $250 \mathrm{~m}$ until sunrise, (4) the RL is detected by both the WP/SNR (light blue circles) and the lidar/ASR (green circles) at $1500 \mathrm{~m}$, the WP catching another turbulent layer at 700-800 $\mathrm{m}$ between 03:00 and 09:00 corresponding to a jet of northeasterly wind $\left(15 \mathrm{~m} \mathrm{~s}^{-1}\right.$, not shown). These two layers measured by WP/SNR and lidar/ASR before sunrise are finally merged into the developing CBL at 07:00 and 09:00, respectively.

- The CBL development from sunrise to mid-afternoon: (1) one hour after sunrise, the CBL height increase is very well caught by all the methods based on $T$ profiles, MWR/bR and COSMO-2/bR showing a quicker $\mathrm{CBL}$ increase and a higher CBL height between sunrise 


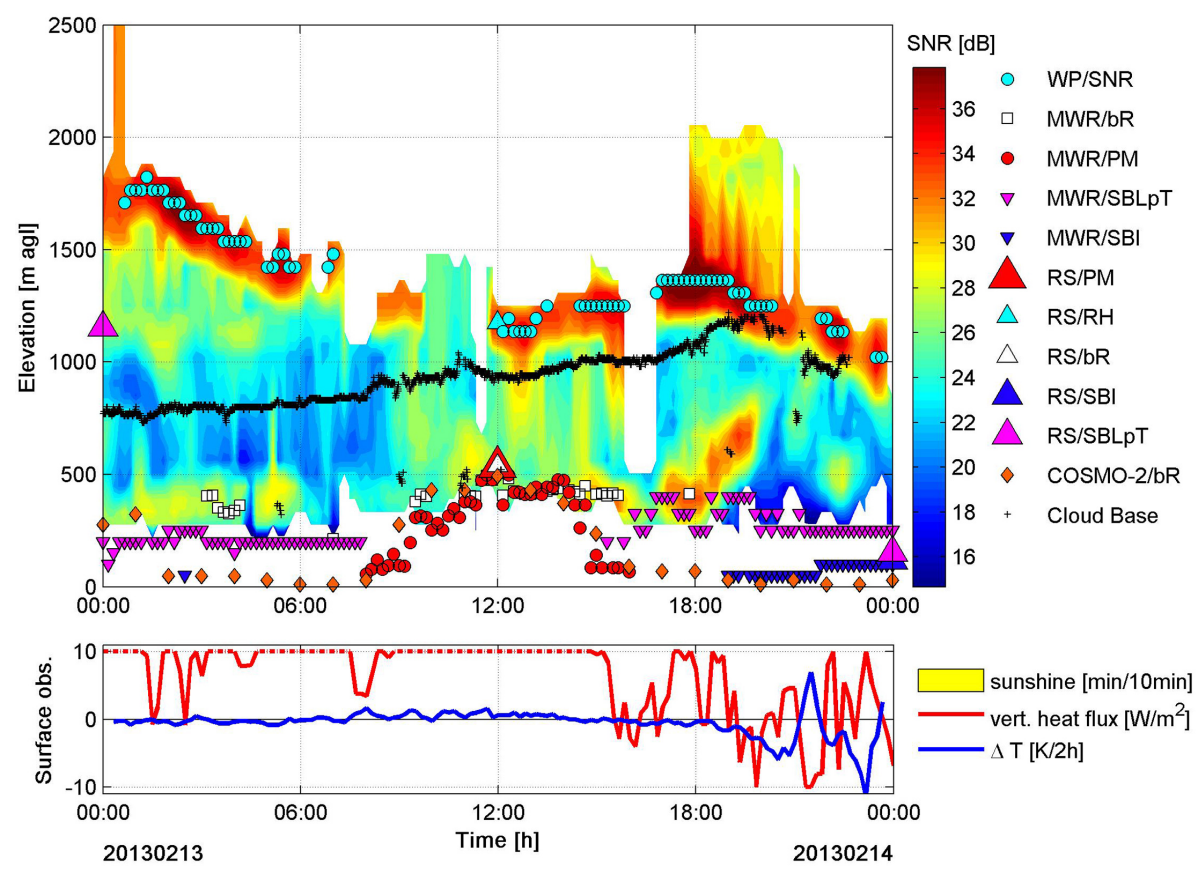

Figure 5. Example of cloudy-CBL detection under cloudy conditions in winter (14 February 2013) plotted on WP/SNR signal as background. For symbol description see Fig. 4.

Table 2. Linear regression of PBL height detected by $\theta_{\mathrm{V}}$ as a function of the PBL height detection by $\theta$ : slope, intercept, coefficient of determination between the data and the fit $\left(R^{2}\right)$, coefficient of determination between the data and the $1: 1$ line $\left(R_{\mathrm{th}}^{2}\right)$, root mean square error of the $x-y$ difference (RMS), median of the difference between $x$ and $y$ coordinates (median bias) and the number of considered data $(N)$. The results are given for PM and bR methods applied to RS and MWR data.

\begin{tabular}{lrrrrrrr}
\hline $\begin{array}{l}\text { Instrument/ } \\
\text { method }\end{array}$ & Slope & Intercept & $R^{2}$ & $R_{\text {th }}^{2}$ & $\begin{array}{r}\text { RMS } \\
{[\mathrm{m}]}\end{array}$ & $\begin{array}{r}\text { Median } \\
\text { bias [m] }\end{array}$ & $N$ \\
\hline RS/PM & 1.08 & -12 & 0.95 & 0.92 & 110 & 18 & 35 \\
RS/bR & 1.05 & 5 & 0.97 & 0.94 & 99 & 26 & 35 \\
MWR/PM & 1.03 & 104 & 0.95 & 0.84 & 161 & 117 & 437 \\
MWR/bR & 1.05 & 67 & 0.95 & 0.88 & 154 & 93 & 420 \\
\hline
\end{tabular}

and 09:00 than MWR/PM. This difference between the $\mathrm{PM}$ and $\mathrm{bR}$ methods is due to the horizontal wind component that is taken into account in the bR method. In this case, the air moisture seems to have minor influence since the bR method leads to similar results if applied to the $\theta_{\mathrm{v}}$ (COSMO-2) or on $\theta$ profiles (MWR). (2) The CBL remains then constant from 12:00 to 15:00, when the temporal gradient of the ground $T$ vanishes before becoming negative (see the lower panel of Fig. 4). This CBL height maximum is consistently measured by all methods. (3) The CBL decrease after 15:00 is also well depicted by the methods based on $T$ profiles (MWR/bR and MWR/PM), whereas the RL is thereafter measured by the WP/SNR and the lidar/ASR. The PM method, which is devised for CBL detection, becomes nonapplicable as soon as the vertical sensible heat flux becomes negative (see the red curve in the lower panel of Fig. 4), generating a positive or vanishing gradient of $\theta$.

- The nocturnal SBL development: after 18:00, the bR method continues to follow the CBL decrease whereas the development of the nocturnal SBL can be detected by the MWR/SBI and MWR/SBLpT methods.

The second example of a winter day (Fig. 5) presents a stable cloud cover at $800-1200 \mathrm{~m}$. The uniformity of the clouds is evident in the ceilometer measurements. In this cloudyCBL case, only the PBL height detection methods based on $T$ profiles provide reasonable results. Due to the presence of low clouds, the lidar system is powered down and the WP/SNR detects the cloud top, which decreases from about $1800 \mathrm{~m}$ at midnight to $1000 \mathrm{~m} 24 \mathrm{~h}$ later. The cloud thickness diminishes then gradually from about $1000 \mathrm{~m}$ to some hundreds of meters before vanishing at the end of the day. 


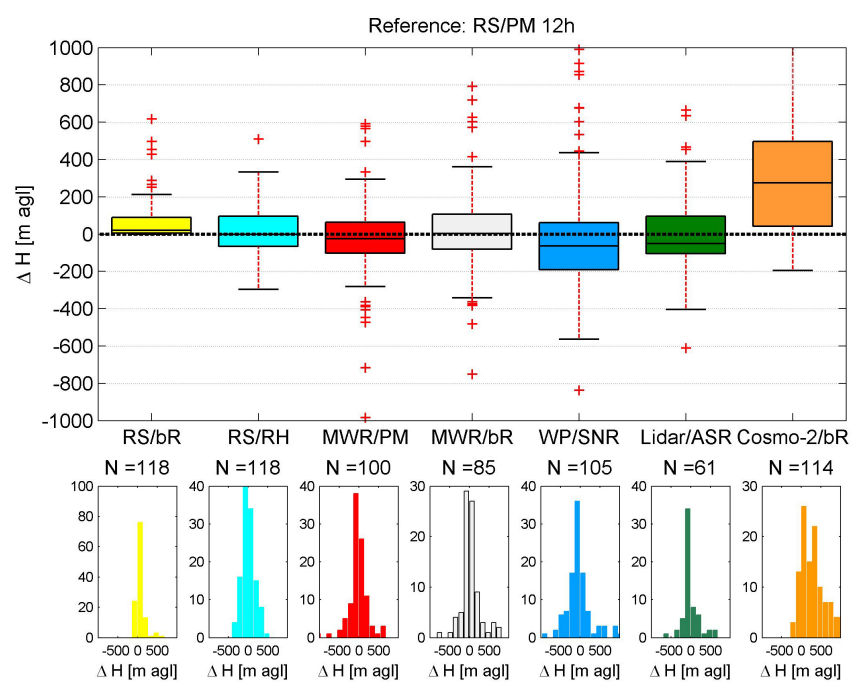

Figure 6. Boxplots of PBL height differences $\Delta H$ between RS/PM and other methods/instrumentation computed at 12:00. The central box line is the median, the edges of the box are the 25th and 75th percentiles ( $q_{1}$ and $q_{3}$ ), the whiskers enclose all data points not considered outliers, and the red crosses are the outliers. Data are considered as outliers if they are larger than $q_{3}+1.5 \cdot\left(q_{3}-q_{1}\right)$ or smaller than $q_{1}-1.5 \cdot\left(q_{3}-q_{1}\right)$, which means that whiskers cover $99 \%$ of data assuming a normal distribution. The $\Delta H$ statistical distribution and the number of data points $\mathrm{N}$ for each boxplot are given in the subplotted histograms, data points greater than $1000 \mathrm{~m}$ being displayed in the last column of the corresponding histogram.

Both the MWR/PM and the COMSMO-2/bR catch very well the cloudy-CBL features such that the peaks at $500 \mathrm{~m}$ during the afternoon and the decrease in height when the vertical heat flux becomes negative. During night, a MWR/SBI is only detected in the evening when the cloud coverage decreases allowing radiative cooling of the ground. MWR/bR is not available most of the time due to a vanishing $\theta$ gradient involving an already positive $R i_{\mathrm{b}}$ at the first level and due to missing wind velocity data from WP at some levels. Also, the available MWR/bR heights are greatly influenced by northerly wind at about $500 \mathrm{~m}$. Similarly, the SBL detected by COSMO- $2 / \mathrm{bR}$ is typically found at the first COSMO-2 level that is attributed to cases with vanishing $\theta$ gradient. The presence of a neutral layer measured by MWR/SBLpT over the ground is detected at a constant height of $200 \mathrm{~m}$ between 00:00 and 08:00.

\subsection{Inter-comparison and validation of the CBL height}

The inter-comparison and validation process was performed at PAY on a set of 119 clear-sky convective days, representing one-third of the total measured days in 2012. This means that the CBL pattern was clearly recognizable and that at least half of the solar radiation was measured from sunrise to 13:00. Hence, the presence of some clouds is not excluded.
$\mathrm{RS} / \mathrm{PM}$ at 12:00 was chosen as the reference method for the validation due to the availability and reliability of RS $T$ profiles and the stability of PM method. The following conclusions can be drawn from the measurements (Table 3 and Fig. 6):

- Due to the use of the same RS data with a very good vertical resolution, the RS/bR and RS/RH gradient methods are the closest to RS/PM, with regression slopes near 1 , coefficients of determination $\left(R^{2}\right)$ with the fit or with the $1: 1$ line greater than or equal to 0.85 and a very small median bias. As expected from the bR definition, its PBL heights are higher than the ones computed by PM, the median bias remaining however very low (about $20 \mathrm{~m}$ ).

- The MWR results are somewhat more scattered, but with very small median bias $(<25 \mathrm{~m})$ and interquartile ranges $(100 \mathrm{~m})$. The MWR/PM has the smallest interquartile ranges and whiskers size due to the same applied detection method that, contrary to bR, do not use the WP wind velocity.

- The WP/SNR method has the lowest correlation coefficients $(0.49)$, the largest median bias $(-64 \mathrm{~m})$ and the largest interquartile range ( -560 to 460$)$ of all the experimental methods considered. It also contains several large positive outliers that may be explained by the detection of elevated cloud layers falsely attributed to PBL height.

- The comparison with lidar/ASR can only be done on a reduced data set (61 cases) due to its lower data availability. Taking into account the very different detection methods based, respectively, on $T$ and aerosol profiles, the comparison with RS/PM is very good with a slope of 1.00 , correlation coefficients of 0.81 and a median bias of $-50 \mathrm{~m}$.

Since the CBL may not always be at its maxima at 12:00, an inter-comparison on the same set of 119 convective days was performed with MWR/PM as reference for the 12:00-15:00 time interval corresponding to CBL height maxima for all seasons (Fig. 7). Similarly to the 12:00 case, the difference between PM and bR is rather small, with interquartile ranges of 5 and $71 \mathrm{~m}$ and whiskers far below $200 \mathrm{~m}$. The lidar/ASR also shows a very good agreement with a median bias of $20 \mathrm{~m}$ and an interquartile range of about $\pm 150 \mathrm{~m}$. Finally the great number of false detections of the WP due to either cloud, high humidity layers or turbulence effects are visible in the larger WP/SNR median bias $(71 \mathrm{~m})$ and interquartile range of about $200 \mathrm{~m}$.

Each of the considered methods and instruments has their own uncertainties in PBL height detection. The uncertainty minimum is usually obtained for fully developed CBL reported in Figs. 6-7. Several type of uncertainties can however be estimated. First, a statistical uncertainty (see for example 
Table 3. Linear regression of PBL height computed with various methods and instruments as a function of RS/PM. See Table 2 for parameters description.

\begin{tabular}{lrrrrrrr}
\hline $\begin{array}{l}\text { Instrument/ } \\
\text { method }\end{array}$ & Slope & Intercept & $R^{2}$ & $R_{\text {th }}^{2}$ & $\begin{array}{r}\text { RMS } \\
{[\mathrm{m}]}\end{array}$ & $\begin{array}{r}\text { Median } \\
\text { bias [m] }\end{array}$ & $N$ \\
\hline RS/bR & 1.02 & 46 & 0.95 & 0.93 & 122 & 21.5 & 118 \\
RS/RH & 1.01 & 3.64 & 0.86 & 0.90 & 154 & 0 & 118 \\
MWR/PM & 0.89 & 73 & 0.75 & 0.74 & 228 & -25.5 & 100 \\
MWR/bR & 0.84 & 173 & 0.72 & 0.69 & 239 & 2.33 & 85 \\
WP/SNR & 0.73 & 210 & 0.49 & 0.41 & 351 & -64 & 105 \\
Lidar/ASR & 1.00 & -3 & 0.81 & 0.81 & 211 & -50 & 61 \\
COSMO-2 & 1.20 & 141 & 0.72 & 0.43 & 472 & 275 & 114 \\
\hline
\end{tabular}

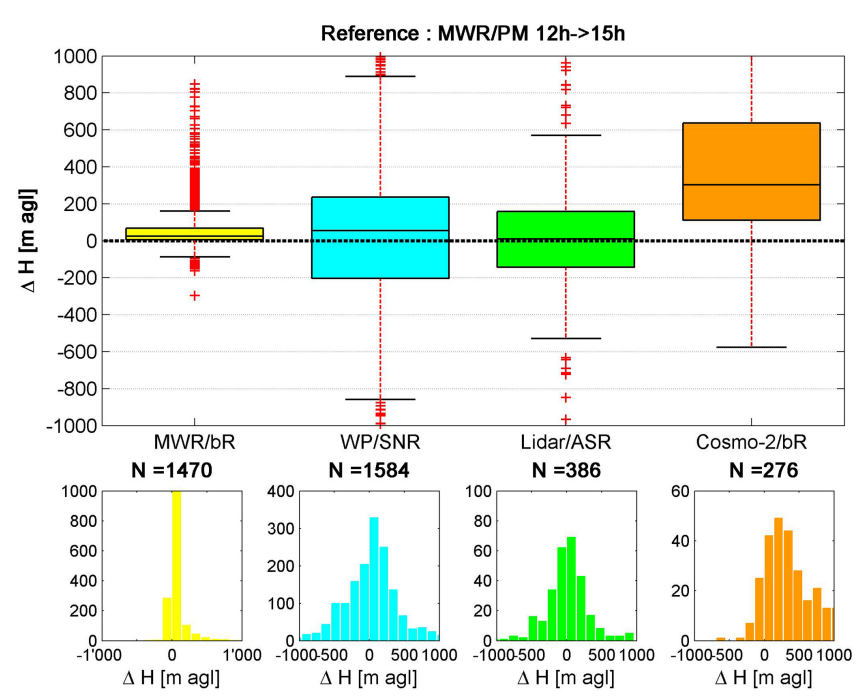

Figure 7. Same as Fig. 6 but between 12:00 and 15:00 UT and with MWR/PM taken as the reference.

the climatology analyses Figs. 9-12) estimates the fluctuations of measurements for cases that are considered as similar; these fluctuations reflect the measurement uncertainties and illustrate the variation of the atmosphere for "similar conditions", but are unable to detect systematic bias. A measuring uncertainty can in addition be derived for each instrument providing an estimation of systematic bias and fluctuations; such analyses have been up to now only partially made for some instruments, but not all, impeding our ability to propagate these errors on the various PBL height detection methods. Finally, the comparison to a reference (Figs. 6-7) allows one to statistically estimate the reliability of the other methods. The uncertainties bounded to the methods and the instruments (see Sect. 2.2) provide however a similar picture as the inter-comparison, with the greatest precision for methods based on $T$ profile and the lowest for WP/SNR.

Finally, in addition to considering the differences in statistical and intrinsic uncertainties found between the various instruments and methods, one has to consider that the measured parameter (PBL height) is in reality not a fixed point but rather a transition layer between two atmospheric states. Both Stull (1988) and Garratt (1992) estimated the thickness of the entrainment zone as large as half the mixed layer depth. This transition layer reaches therefore between some tens to some hundreds of meters. Moreover, the remote sensing instruments measure an air volume with a thickness corresponding to the instrument level (see Sect 2.2) and not a precise point. The obtained differences between the experimental methods and their uncertainties remain on the same order of magnitude of this transition layer thickness.

\subsection{Comparison between PBL height measured and computed by COSMO-2}

The comparison of the COSMO-2/bR PBL heights to the references for the same 119 cases described in Sect. 3.3 (Table 3 and Figs. 6 and 7) shows that the PBL heights calculated by COSMO-2/bR have a positive bias compared to the measured PBL heights. The median biases are $275 \mathrm{~m}$ and $299 \mathrm{~m}$ when compared to the RS/PM (12:00) and to the MWR/PM (12:00 to $15: 00$ ), respectively. The interquartile ranges reach 200 to $350 \mathrm{~m}$, and the maximal whiskers are higher than $1000 \mathrm{~m}$. A detailed analysis of the individual determinations (see Fig. 8 for example) reveals that COSMO-2/bR often overestimates the PBL height during the whole day and tends to show a toorapid PBL growth in the morning. This behavior is not limited to clear-sky convective days and is observed throughout the year. This significant positive bias compared to all experimental methods and the asymmetry of the distribution, which is seen on the histograms (Figs. 6 and 7), may have several explanations:

- Contrary to all the experimental methods, COSMO2/bR determines the PBL height from the $\theta_{\mathrm{v}}$ profile, not the $\theta$ profile, leading to a physically caused systematic positive difference (see Sect. 3.1). This bias of 3-8\% (see Sect. 3.1) cannot however completely explain the large discrepancy with the experimental methods.

- The use of the bR method induces a positive bias compared to the PM method, but the difference does not ex- 

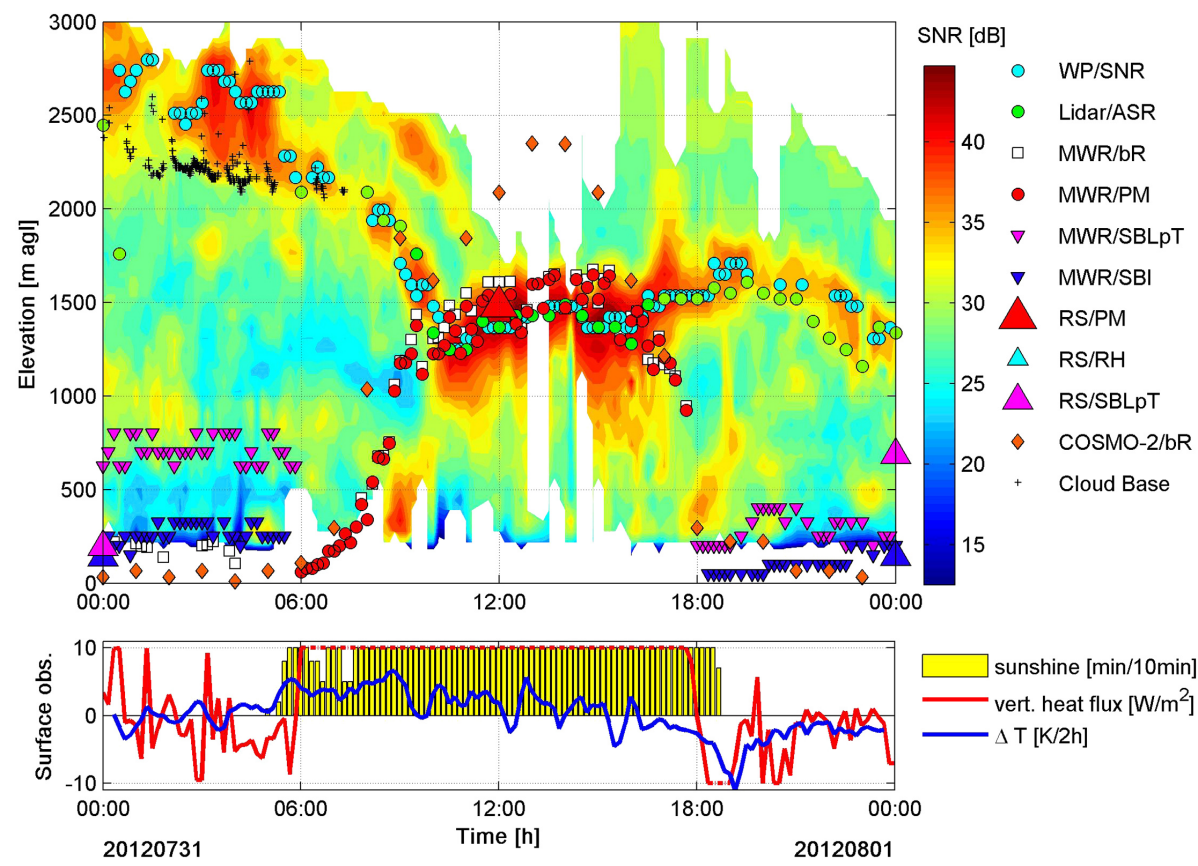

Figure 8. Example of CBL overestimation by COSMO-2/bR, the background signal corresponds to the WP/SNR. For a description of the symbols, see Fig. 4.
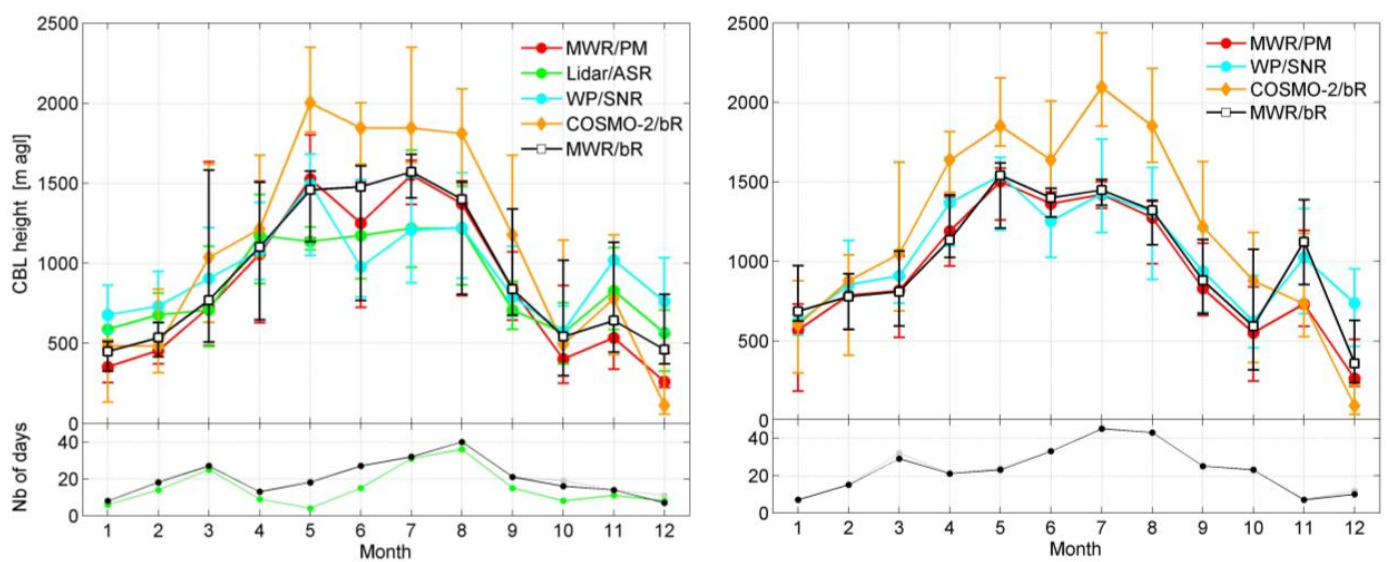

Figure 9. Upper panel: CBL height 2-year climatology at PAY (left) and SHA (right). The symbols are the monthly median of the daily medians of the CBL height taken between 12:00 and 15:00; the error bars are the 25th and 75th percentiles. Lower panel: the number of CBL days used for calculating the monthly medians are given in grey for MWR/PM, WP/SNR and COSMO-2/bR, in black for MWR/bR and in green for lidar/ASR.

ceed some tens of meters as demonstrated by the RS and MWR results.

- The bR method is very sensitive to the surface $T$ and an overestimation of this parameter induces a systematic positive bias of PBL height as can be seen from Eq. (1). Errors and uncertainties in both $T$ and RH profiles of COSMO-2 could also explain the large observed bias.

- The occurrence of clouds, which may be missing in the model, can temporarily reduce the surface heating and thus, the convection of air masses. Therefore the occurrence of clouds can lead to a lower measured PBL height.

Further studies are necessary to assess the details of how these various parameters cause the PBL height overestimated in COSMO-2/bR, but our results demonstrate the model consistently overestimates the PBL height. 

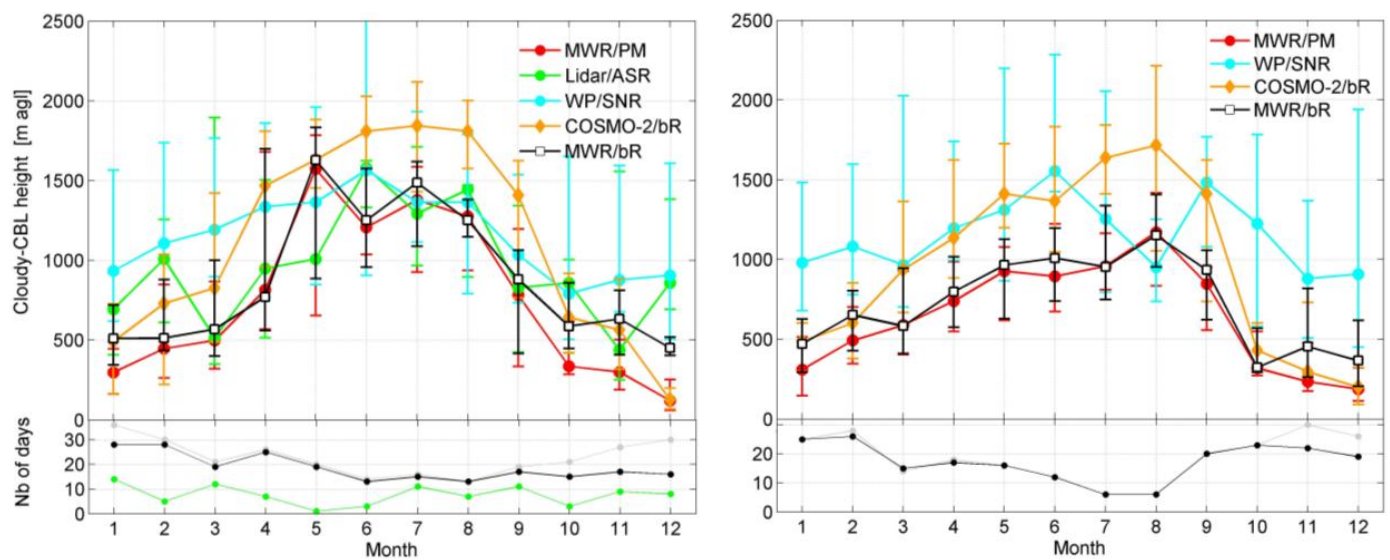

Figure 10. Upper panel: cloudy-CBL height climatology at PAY (left) and SHA (right). Lower panel: number of cloudy-CBL days used to calculate the monthly medians. Symbols and colors as in Fig. 9.
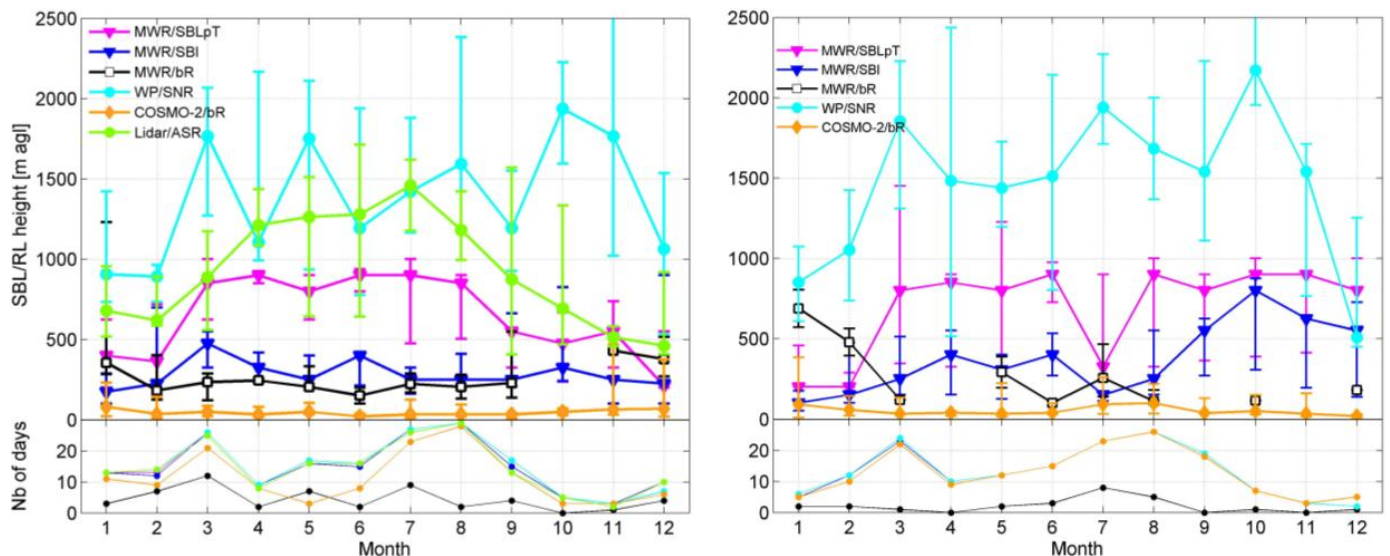

Figure 11. Upper panel: SBL and RL heights for clear-sky conditions at PAY (left) and SHA (right). Lower panel: number of cloudy-CBL days used to calculate the monthly medians for each method, the colors correspond to the upper panel ones. Symbols and colors as in Fig. 9.

\subsection{PBL height 2-year climatology at PAY and SHA}

\subsubsection{CBL climatology}

The 2-year climatology of CBL heights calculated from all instruments and COSMO-2 is presented in Fig. 9 for PAY (256 days) and SHA (289 days). It has to be noted that the same subset of days was taken for the MWR, the WP and COSMO-2, whereas the lower availability of lidar/ASR data and to a lesser extent of MWR/bR leads to a smaller data set that is still useful for comparison with the CBL heights estimated from the other instruments. The CBL heights have an annual cycle with a minima at $300-700 \mathrm{~m}$ in winter and a maxima at $1200-1500 \mathrm{~m}$ during the May-August period. It has to be noted that the CBL extremes occur at the solstices and not at the $T$ extremes (January-February and JulyAugust), suggesting that solar insolation would be a better climatic variable to predict CBL cycle than the $T$.

The systematic overestimation of the COSMO-2/bR model observed at both stations presents a clear annual cy- cle with a winter minimum and a summer maximum that can reach 500-700 m. At PAY and to a lesser extent at SHA, the WP/SNR and lidar/ASR detect a higher CBL (300-500 m) than the MWR/PM and MWR/bR in winter. This difference is probably related to meteorological conditions with highaltitude $T$ inversion leading to a stable and sometimes decoupled aerosol layer at altitudes higher than the CBL top. The lidar/ASR measurement of this aerosol layer top should rather be attributed to an RL than a CBL height and the WP/SNR measures the turbulence resulting from wind shear at the $T$ inversion altitude.

The CBL maxima measured over the Swiss plateau are similar to the PBL heights maxima measured over Europe by RS (Seidel et al., 2012; Beyrich and Leps, 2012), but lower than the lidar-measured PBL height over Leipzig (Baars et al., 2008) and the PBL height detected by several methods (RS, MWR and lidar) over Granada (Granados-Muños et al., 2012). The higher PBL height over both regions can be explained for Leipzig by its lower altitude (135 $\mathrm{m}$ a.s.l.), its 

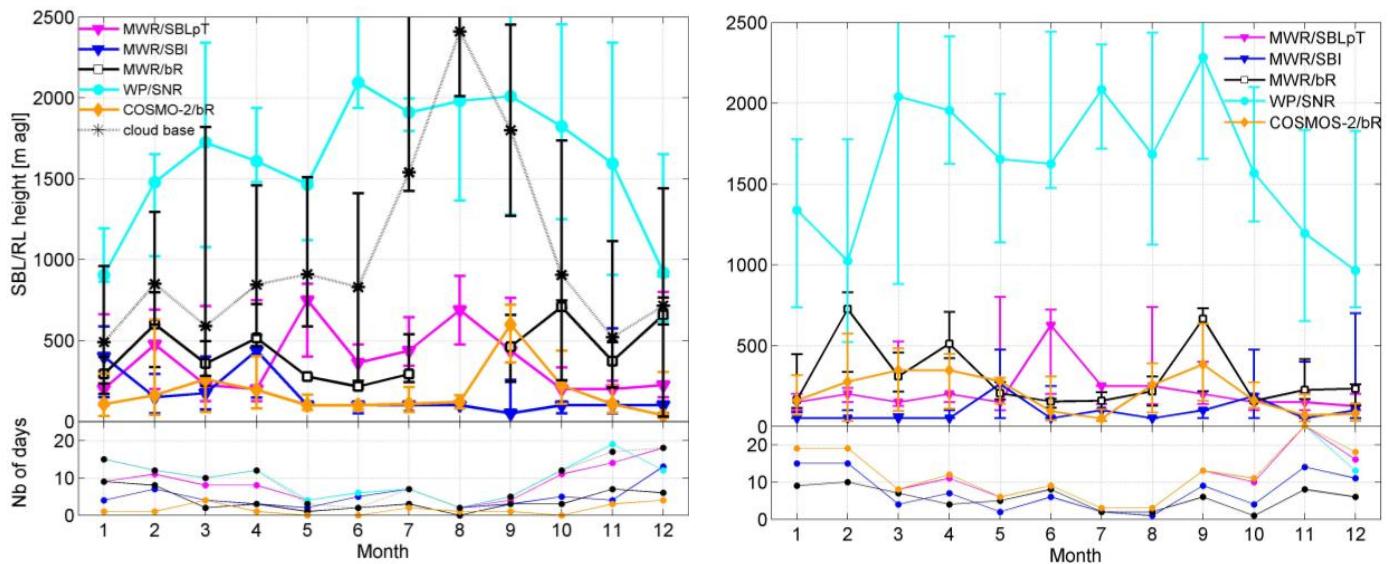

Figure 12. Upper panel: SBL and RL heights for cloudy conditions at PAY (left) and SHA (right). Lower panel: number of cloudy-CBL days used to calculate the monthly medians, the colors correspond to the upper panel ones. Symbols and colors as in Fig. 9.

northerly latitude leading to longer summer days and similar annual $T$ cycle $\left(0^{\circ} \mathrm{C}\right.$ in winter and $18^{\circ} \mathrm{C}$ in summer; www.dwd.de), and for Granada by the far greater mean $T$ $\left(6^{\circ} \mathrm{C}\right.$ in winter and $25^{\circ} \mathrm{C}$ in summer; www.aemet.es) even if the city lies at higher altitude (730 $\mathrm{m}$ a.s.1.) than PAY.

\subsubsection{Cloudy-CBL climatology}

Cloudy-CBL cases have been selected as non-CBL days without rain between 06:00 and 15:00 and correspond to various meteorological conditions (e.g., high-altitude clouds, fog, advection, mixed conditions). As expected by its more heterogeneous atmospheric structure, the cloudy-CBL climatology (271 days at PAY and 223 at SHA) presents more scattered results with larger quartiles (Fig. 10) than the CBL one. The cloudy-CBL annual cycle based on the $T$ profile (MWR/PM, MWR/bR and COSMO-2/bR) is maximal in summer and minimal in winter similarly to the CBL cycle, but with lower PBL heights. The difference between CBL and cloudy-CBL heights is greater at SHA $(500-700 \mathrm{~m})$ than at PAY $(<300 \mathrm{~m})$. COSMO-2/bR cloudy-CBL height has a positive bias compared to MWR/PM and MWR/bR at both stations, and this overestimation is usually greater than for the CBL case. The WP/SNR cloudy-CBL heights are most of the time more than $500 \mathrm{~m}$ higher than MWR/PM ones; $45 \%$ of these cloudy-CBL heights detected by WP/SNR are however higher than the cloud-base detected by the ceilometer. The WP/SNR measures in those cases the cloud top (see for example Fig. 5). For PAY, a flagging system involving the cloud-base detection could correct for these false attributions of the PBL height. Despite the low amount of available measurements, the lidar/ASR PBL heights are similar to MWR/PM PBL heights in summer and higher in winter, leading to similar results as for the CBL climatology.

\subsubsection{SBL climatology}

The SBL climatology was divided into clear-sky (Fig. 11) and cloudy nights (Fig. 12) in order to differentiate cases with high and low radiative cooling. Clear-sky (186 at PAY and 163 at SHA) and cloudy nights (126 at PAY and 151 at SHA) were selected with the criteria of no precipitation between 00:00 and 05:00 in addition to 0-2 and 7-8 octa of the sky covered by clouds estimated by APCADA, respectively. While some features of the SBL annual behavior can be deduced, the low number of cases for some months, particularly for cloudy conditions, does not allow us to draw strict conclusions on the effective seasonal cycle of the different layers forming the SBL. The following points can however be inferred:

- During clear-sky nights, the complete SBL structure can be clearly observed at PAY with SBI heights being between 100 and $500 \mathrm{~m}$ during the whole year, SBLpT being lower than $500 \mathrm{~m}$ in winter and rising up to $800 \mathrm{~m}$ during the other seasons. The RL measured by the lidar/ASR has a seasonal cycle completely similar to the CBL one (see Fig. 9), so that the pollutant emitted during the preceding days remain at the altitude of the CBL maxima during the night.

- During clear-sky nights, the WP/SNR method, which is more frequently subjected to false attribution than the other methods (see Sect. 2.2.2), leads to much more scattered results and large quartiles. The WP/SNR results are however comparable to the RL heights measured by the lidar/ASR.

- During cloudy nights, the ground $T$ remains higher due to lower radiative cooling and a different SBL structure is observed. First, the SBI is found at a lower altitudes (100-200 m) than during clear-sky nights; second, the SBLpT also reaches lower altitudes remaining usually 
under $500 \mathrm{~m}$; third, the cloud base is found between 500 and $2400 \mathrm{~m}$; finally, the cloud top is measured by the WP/SNR between 1000 and $2000 \mathrm{~m}$. A mean cloud depth between 200 and $1000 \mathrm{~m}$ is therefore measured over PAY. One can say that the various SBL heights measured by $T$ profiles are all compressed under 500 $800 \mathrm{~m}$ by the cloud base.

- The COSMO-2/bR frequently computes SBL height lower than $50 \mathrm{~m}$ that can hardly represent a real physical PBL height. These false estimations are due to a stable $\theta$ profile near ground leading to an already positive $b R$ number at the first levels and occurring more frequently during calm and clear-sky nights with large ground radiative cooling than during cloudy nights with higher surface $T$ and less turbulence. This phenomenon is clearly visible in Fig. 11: in the case of clear-sky nights, COSMO-2/bR SBL heights are always lower or equal to $50 \mathrm{~m}$ whereas MWR/bR measures a higher valid SBL height but in much fewer cases (see lower panels). During cloudy nights (Fig. 12), COSMO-2/bR produces more reliable results with SBL heights on the same order of magnitude than the MWR/SBI, MWR/bR and MWR/SBLpT methods.

- The MWR/bR method gives results usually similar to SBI in the case of clear-sky but clearly higher in the case of cloudy nights. This difference is probably due to the direct dependence of SBI height on the ground radiative cooling, whereas the bR method is more affected by wind turbulence and katabatic jets that are not discriminated by the cloud amount.

Few SBL climatologies have been yet published probably due to the greater complexity of PBL heights detection during night than during day. Cimini et al. (2013) found MWR/SBL height lower than $500 \mathrm{~m}$ near Paris during the March-August period that are comparable to our climatology over the Swiss plateau. Martucci et al. (2007) found nighttime RL heights detected by lidar/ASR between 500 and $1500 \mathrm{~m}$ in Neuchâtel (Switzerland), similar to our results. Additionally, Beyrich and Leps (2012) and Seidel et al. (2010) studied the 10-year climatology of PBL height detected by RS measurements (twice a day). The SBL seasonal cycles over Europe were found to depend on the method applied to the RS profiles: the PM method leads to almost constant SBL during the whole year, whereas SBI has a seasonal minima in summer and a maxima in winter. Unfortunately, our 2-year data set restricted by the cloud coverage is not large enough to compare our SBL seasonal cycles with these results. Finally, similarly to our results, the gradient method applied to the RH or specific humidity profiles is maximal during summer and minimal during winter. As expected, they also found that SBI yields the smallest heights, followed by the PM method, while the humidity and the ASR profiles similarly lead to much greater heights, corresponding to RL top.

\section{Conclusion: strengths and limitations of an operational mode}

The difficulty of the PBL height detection comes first from the complexity of the troposphere itself, which can be composed of several layers with different thermal structures, wind regimes and concentrations of atmospheric constituents. Secondly, each detection method has good performances only for defined PBL structures and under specific meteorological conditions. Only the combination of several methods and instruments allows one to follow the complete diurnal cycle of the complex PBL layered structure.

For this study a system for automatic realtime detection of the PBL height based on several methods applied to various remote sensing observations was implemented and operated for 2 years (2012-2013) for two upper-air stations on the Swiss plateau to quantify the advantages and disadvantages of several techniques. The numerical weather prediction model COSMO-2/bR PBL height was also compared to the experimentally determined PBL heights. Relative RS/PM at $12: 00$ or the MWR/PM between 12:00 and 15:00 as a reference, the remote sensing and model results were then validated on a subset of 119 convective days. A 2-year climatology for daytime and nighttime PBL heights was calculated for convective days and clear-sky nights, as well as for cloudy convective days and nights without precipitation. The system for automatic detection of the PBL height is now implemented in an operational environment and the data are visualized and provided to end users in realtime.

The advantages and limitations of each detection/measurement method as an operational mode are summarized in Table 4. The greatest advantage of PBL detection by the various profiles measured by RS is its very good measurement precision and vertical resolution. Its temporal resolution (two measurements per day), however, does not provide the PBL diurnal cycle.

The MWR provides $T$ profiles under all non-precipitating conditions with a lower vertical but a higher temporal resolution than RS, allowing the analysis of the whole PBL diurnal cycle. The four PBL height detection methods applied to MWR data allow the following conclusion to be drawn:

1. The PBL increases after sunrise, reaching its maximal elevation at the beginning of the afternoon and then decreasing as soon as the vertical heat flux vanishes after sunset.

2. The SBI development and maximal height from sunset to sunrise that corresponds to the layer in which the pollutants emitted during the night are trapped.

3. MWR/SBLpT measures the top of the nocturnal stable layer. MWR is therefore able to detect the daytime and 
Table 4. Advantages and limits of detection methods and instruments to estimate the PBL height.

\begin{tabular}{|c|c|c|c|c|}
\hline Method & Profiles & $\begin{array}{l}\text { PBL height } \\
\text { detected }\end{array}$ & Advantages & Limits \\
\hline PM & $\theta$ or $\theta_{v}$ & $\begin{array}{l}\text { CBL, cloudy- } \\
\text { CBL }\end{array}$ & $\begin{array}{l}\text { - also efficient under weak } \\
\text { convective condition } \\
\text { - early growth after sunrise until } \\
\text { decrease when temporal gradient } \\
\text { of surface } T \text { and vertical heat flux } \\
\text { become negative }\end{array}$ & $\begin{array}{l}\text { - requires negative gradient } \\
\text { in } \theta \text { at the ground } \\
\text { - not available during night }\end{array}$ \\
\hline bR & $\begin{array}{l}\theta \text { or } \theta_{v}+ \\
\text { wind }\end{array}$ & $\begin{array}{l}\text { CBL, cloudy- } \\
\text { CBL, SBL }\end{array}$ & $\begin{array}{l}\text { - nighttime and daytime } \\
\text { detection } \\
- \text { transition between SBL and } \\
\text { CBL at sunrise } \\
\text { - CBL decrease also after the ver- } \\
\text { tical heat flux and temporal } T \\
\text { gradient become negative }\end{array}$ & $\begin{array}{l}\text { - requires wind profiles } \\
\text { from WP or RS } \\
\text { - often false SBL detection } \\
\text { in the case of constant } \theta \\
\text { profile }\end{array}$ \\
\hline SBI & $T$ & SBL & $\begin{array}{l}\text { - SBI formation after sunset } \\
\text { - describe the layer where the } \\
\text { pollutants emitted during night } \\
\text { are trapped }\end{array}$ & \\
\hline SBLpT & $\theta$ or $\theta_{v}$ & SBL & $\begin{array}{l}\text { - Formation and top of the stable } \\
\text { nocturnal layer }\end{array}$ & $\begin{array}{l}\text { - no well-defined limit of } \\
\text { the SBL layered structure }\end{array}$ \\
\hline $\begin{array}{l}\text { Aerosol/ } \\
\text { humidity } \\
\text { gradient }\end{array}$ & ASR, RH & $\mathrm{CBL}, \mathrm{RL}$ & $\begin{array}{l}\text { - measures the dynamics of } \\
\text { aerosol dispersion } \\
\text { - a real measure of the pollutants } \\
\text { ML }\end{array}$ & - no measure of the SBL \\
\hline $\begin{array}{l}\text { SNR } \\
\text { maxima }\end{array}$ & wind & CBL, (RL) & $\begin{array}{l}\text { - sometimes retrieves PBL height } \\
\text { early growth after sunrise } \\
\text { - only method based on the } \\
\text { vertical structure of turbulence. }\end{array}$ & $\begin{array}{l}\text { - large number of outliers } \\
\text { due to false attributions } \\
\text { - can also retrieve the cloud } \\
\text { top }\end{array}$ \\
\hline Instrument & Profiles & $\begin{array}{l}\text { PBL height } \\
\text { detected }\end{array}$ & Advantages & Limits \\
\hline $\begin{array}{l}\text { Microwave } \\
\text { radiometer }\end{array}$ & $T$, RH, wind & $\begin{array}{l}\text { CBL, cloudy- } \\
\text { CBL, SBL }\end{array}$ & $\begin{array}{l}\text { - captures diurnal cycle } \\
\text { - good data availability } \\
\text { - good temporal resolution }\end{array}$ & - low vertical resolution \\
\hline Wind profiler & $\begin{array}{l}\text { Wind, SNR } \\
\text { ratio }\end{array}$ & $\mathrm{CBL}, \mathrm{RL}$ & $\begin{array}{l}\text { - daily cycle } \\
\text { - can also retrieve the cloud top- } \\
\text { based on the vertical structure of } \\
\text { turbulence. }\end{array}$ & $\begin{array}{l}\text { - no PBL detection in the } \\
\text { case of precipitation } \\
\text { - low data availability at } \\
\text { low altitude }\end{array}$ \\
\hline Lidar & ASR, RH & $\mathrm{CBL}, \mathrm{RL}$ & $\begin{array}{l}\text { - daily cycle } \\
\text { - direct measurement of } \\
\text { atmospheric composition }\end{array}$ & $\begin{array}{l}\text { - no data in the case of fog, } \\
\text { low clouds } \\
\text { - needs maintenance }\end{array}$ \\
\hline $\begin{array}{l}\text { Radio } \\
\text { sounding }\end{array}$ & $\begin{array}{l}T, p, \mathrm{RH}, \\
\text { wind }\end{array}$ & $\begin{array}{l}\text { CBL, cloudy- } \\
\text { CBL, SBL }\end{array}$ & $\begin{array}{l}\text { - most accurate and precise data } \\
\text { - best vertical resolution }\end{array}$ & $\begin{array}{l}\text { - only twice a day at } 00: 00 \\
\text { and } 12: 00\end{array}$ \\
\hline
\end{tabular}

nighttime layers in which ground-emitted atmospheric constituents are trapped, but not the RL corresponding to the air volume trapping the atmospheric constituents emitted some hours/days before.

The Raman lidar has a higher vertical resolution than MWR but its data availability is restricted by fog, low cloud coverage and precipitation. The profiles of the aerosol or the humidity concentrations allow one to measure the dynamics of atmospheric constituents and are consequently a direct deter- mination of the pollutant dispersion in the PBL. The comparison with RS/PM and MWR/PM proves that the lidar/ASR is able to detect the CBL maxima during the afternoon with a good precision and also sometimes part of the CBL formation. During night, this method provides the RL height and can therefore be considered as complementary to the MWR methods.

The comparison of WP/SNR with RS/PM and MWR/PM shows that, in most cases, the CBL maximum is well de- 
tected by WP, but with a lower precision and a greater amount of outliers. De facto WP/SNR maxima can be generated by turbulence at the PBL top, but also at cloud top or at wind shears. An operational PBL height measurement by WP is therefore much more difficult to implement without a human visual control to attribute the SNR maxima to the real atmospheric phenomena. In the case of cloudy condition, the WP/SNR tends to measure the cloud top instead of the PBL height, which could be exploited for other applications. For this study, the WP and the Raman lidar have been used in their operational configuration. However, it would technically be possible for both systems to go to higher temporal and vertical resolutions optimized for PBL height detection, which could slightly improve their performance. Moreover, more complex procedures for the CBL height detection and for the selection of clear CBL cases can greatly increase the accuracy of the results, but decrease the availability of the CBL height detection (see for example Bianco et al. 2008).

The forecast model COSMO-2 uses the bR method applied to the $\theta_{\mathrm{v}}$ profile and relies therefore on bR qualities (day and night detection, detection of CBL growth, maxima and decrease) and weaknesses (often false detection during night particularly in the case of clear-sky conditions). COSMO2/bR is found to often overestimate both CBL and cloudyCBL by $500-1000 \mathrm{~m}$. The most probable causes for this discrepancy are systematic differences in terms of surface $T, T$ or RH profiles. This issue will be addressed in future work. The SBL detection during night is attributed to the lowest level in the case of stable $\theta_{\mathrm{V}}$ gradient, which could lead to a misinterpretation of this value that does not really correspond to a PBL height. To avoid such a misunderstanding, a missing or flagged value should be introduced instead of the lowest level for these cases.

We conclude that the MWR/PM is the most robust among the experimental methods under consideration and best suited for automatic realtime detection of the PBL height. It provides good results under a wide range of meteorological conditions. Moreover, the MWR/SBI and SBLpT allow the characterization of the nocturnal SBL. It is however necessary to have access to a ceilometer or lidar to monitor the RL height.

Taking advantage of all available upper-air measurements, the principal features of the PBL are well depicted by the 2year climatology. The annual cycle of the CBL height with its maxima at $1500 \mathrm{~m}$ during the May-August period is detected by all instruments and seems to follow the solar radiation cycle rather than the $T$ cycle. During partial or total cloud conditions, a similar annual cycle occurs, but with lower PBL heights. The WP results are however strongly influenced by wind turbulence at the cloud top. The nocturnal PBL structure can be clearly observed under clear-sky conditions, with the SBI height remaining rather constant throughout the year at $200-300 \mathrm{~m}$, the top of the stable layer at $800 \mathrm{~m}$ for most of the non-winter months and finally the RL nocturnal seasonal cycle following the CBL diurnal maximal. In the case of to- tal cloud coverage, the SBI height is lower than in the case of clear sky, and the SBL layers seems to be compressed and not well structured under the cloud base. Further meteorological phenomena such as fog, neutral boundary layer height, main pollutant advection or nocturnal jets will be further addressed either as case studies or statistically after a longer measurement period.

Acknowledgements. The authors greatly acknowledge Robert Sica for reviewing the manuscript.

Edited by: J.-Y. C. Chiu

\section{References}

Angevine, W. M., White, A. B., and Avery, S. K.: Boundary-layer depth and entrainment one characterization with a boundary layer profiler. Bound.-Lay. Meteorol., 68, 375-385, 1994.

Baars, H., Ansmann, A., Engelmann, R., and Althausen, D.: Continuous monitoring of the boundary-layer top with lidar, Atmos. Chem. Phys., 8, 7281-7296, doi:10.5194/acp-8-7281-2008, 2008.

Beyrich, F. and Leps, J.-P.: An operational mixing height data set from routine radiosoundings at Lindenberg: methodology, Meteorol. Z., 21, 337-348, 2012.

Bianco, L. and Wilczac, J. M.: Convective boundary layer depth: improved measurement by doppler radar wind profiler using fuzzy logic methods, J. Atmos. Ocean. Technol., 19, 1745-1758, 2002.

Bianco, L., Wilczak, J. M., and White, A. B.: Convective boundary layer depth estimation from wind profilers: statistical comparison between an automated algorithm and expert estimations, J. Atmos. Ocean. Technol., 25, 1397-1413, doi:10.1175/2008JTECHA981.1, 2008.

Bradley, R. S., Keimig, F. T., and Diaz, H. F.: Recent changes in the North American Arctic boundary layer in winter, J. Geophys. Res., 98, 8851-8858, doi:10.1029/93JD00311, 1993.

Calpini, B., Ruffieux, D., Bettems, J.-M., Hug, C., Huguenin, P., Isaak, H.-P., Kaufmann, P., Maier, O., and Steiner, P.: Groundbased remote sensing profiling and numerical weather prediction model to manage nuclear power plants meteorological surveillance in Switzerland, Atmos. Meas. Tech., 4, 1617-1625, doi:10.5194/amt-4-1617-2011, 2011.

Cimini, D., De Angelis, F., Dupont, J.-C., Pal, S., and Haeffelin, M.: Mixing layer height retrievals by multichannel microwave radiometer observations, Atmos. Meas. Tech. Discuss., 6, 49714998, doi:10.5194/amtd-6-4971-2013, 2013.

Cost Action 710 - Final report "Harmonisation of the preProcessing of meteorological data for atmospheric dispersion models", edited by: Fisher, B. E. A., Erbrink, J. J., Finardi, S., Jeannet, P., Joffre, S., Morselli, M. G., Pechinger, U., Siebert, P., and Thomson, D. J., European Communities, ISBN 92-8283302-X, Belgium, 1998.

Degreane Horizon: Degrewind PCL 1300 Processing Computer User Manual, Cuers, France, 2006. 
Dinoev, T. S., Simeonov, V. B., Calpini, B., Parlange, M. B., Monitoring of Eyjafjallajökull Ash Layer Evolution over Payerne Switzerland with a Raman Lidar, in: Proceedings of the TECO 2010, Helsinki, Finland, 30 August to 1 September, Keynote 2, 2010.

Dinoev, T., Simeonov, V., Arshinov, Y., Bobrovnikov, S., Ristori, P., Calpini, B., Parlange, M., and van den Bergh, H.: Raman Lidar for Meteorological Observations, RALMO - Part 1: Instrument description, Atmos. Meas. Tech., 6, 1329-1346, doi:10.5194/amt-6-1329-2013, 2013.

Dürr, B. and Philipona, R.: Automatic cloud amount detection by surface longwave downward radiation measurements, J. Geophys. Res., 109, D05201, doi:10.1029/2003JD004182, 2004.

Emeis, S.: Surface-based remote sensing of the atmospheric layer, in: Atmospheric and Oceanographic Sciences Library, vol. 40, edited by: Mysak, L. A. and Hamilton, K., Springer, Dordrecht, Heidelberg, London, New York, 171 pp., 2009.

Fisher, B. E. A., Erbrink, J. J., Finardi, S., Jeannet, P., Joffre, S., Morselli, M. G., Pechinger, U., Seibert, P., and Thomson, D. J.: Cost Action 710-Final report: Harmonisation of the Pre-processing of meteorological data for atmospheric dispersion models, Office for Official Publications of the European Communities, Belgium, 1998.

Garrett, J. R.: The atmospheric boundary layer, Cambridge atmospheric and space science series, Cambridge University Press, Cambridge, 1992.

Granados-Muñoz, M. J., Navas-Guzmán, F., Bravo-Aranda, J. A., Guerrero-Rascado, J. L., Lyamani, H., Fernández-Gálvez, J., and Alados-Arboledas, L.: Automatic determination of the planetary boundary layer height using lidar: one-year analysis over southeastern Spain, J. Geophys. Res., 117, D18208, doi:10.1029/2012JD017524, 2012.

Haeffelin, M., Angelini, F., Morille, Y., Martucci, G., Frey, S., Gobbi, G. P., Lolli, S., O’Dowd, C. D., Sauvage, L., XuerefRémy, I., Wastine, B., and Feist, D. G.: Evaluation of mixingheight retrievals from automatic profiling lidars and ceilometers in view of future integrated networks in Europe, Bound.-Lay. Meteorol., 143, 49-75, doi:10.1007/s10546-011-9643-z, 2012.

Holzworth, G. C.: Estimates of mean maximum mixing depths in the contiguous united states, Mon. Weather Rev., 92, 235-242, 1964.

Jericevic, A. and Grisogono, B.: The critical bulk Richardson number in urban areas: verification and application in a numerical weather prediction model, Tellus A, 58, 19-27, 2006.

Ketterer, C., Zieger, P., Bukowiecki, N., Collaud Coen, M., Maier, O., Ruffieux, D., and Weingartner, E.: Investigation of the planetary boundary layer in the Swiss Alps using remote sensing and in-situ measurements, Bound.-Lay. Meteorol., 151, 317334, doi:10.1007/s10546-013-9897-8, 2014.

Liu, S. and Liang, X.-Z.: Observed diurnal cycle climatology of planetary boundary layer height, J. Climate, 23, 5790-5809, doi:10.1175/2010JCLI3553.1, 2010.

Mahrt, L., Sun, J., Blumen, W., Delany, T., and Oncley, S.: Nocturnal boundary-layer regimes, Bound.-Lay. Meteorol., 88, 255278, 1998.
Martucci, G., Matthey, R., Mitev, V., and Richner, H.: Comparison between backscatter lidar and radiosonde measurements of the diurnal and nocturnal stratification in the lower troposphere, J. Atmos. Ocean. Technol., 24, 1231-1244, 2007.

Milroy, C., Martucci, G., Lolli, S., Loaec, S., Sauvage, L., XuerefRemy, I., Lavrič, J. V., Ciais, P., Feist, D. G., Biavati, G., and O’Dowd, C. D.: An Assessment of Pseudo-Operational GroundBased Light Detection and Ranging Sensors to Determine the Boundary-Layer Structure in the Coastal Atmosphere, Advances in Meteorology, 18 pp., doi:10.1155/2012/929080, 2012.

Radiometer Physics GMbH: Technical Instrument Manual, Meckenheim, Germany, 2011.

Salmond, J. A. and McKendry, J. A.: A review of turbulence in the very stable nocturnal boundary layer and its implications for air quality, Prog. Phys. Geog., 29, 171-188, 2005.

Sawyer, V. and Li, Z.: Detection, variations and intercomparison of the planetary boundary layer depth from radiosonde, lidar and infrared spectrometer, Atmos. Environ., 79, 518-528, 2013.

Schmid, P. and Niyogi, D.: A method for estimating planetary boundary layer heights and its application over the ARM Southern Great Plains Site, J. Atmos. Ocean. Technol., 29, 316-322, doi:10.1175/JTECH-D-11-00118.1, 2012.

Seidel, D. J., Ao, C. O., and Li, K.: Estimating climatological planetary boundary layer heights from radiosonde observations: comparison of methods and uncertainty analysis, J. Geophys. Res., 115, D16113, doi:10.1029/2009JD013680, 2010.

Seidel, D. J., Zhang, Y., Beljaars, A. C. M., Golaz, J.-C., Jacobson, A. R., and Medeiros, B.: Climatology of the planetary boundary layer over the continental United States and Europe, J. Geophys. Res., 117, D17106, doi:10.1029/2012JD018143, 2012.

Stull, R. B.: An Introduction to Boundary Layer Meteorology, vol. 13, Kluwer Academic Publishers, the Netherlands, Dordrecht/Boston/London, 1988.

Summa, D., Di Girolamo, P., Stelitano, D., and Cacciani, M.: Characterization of the planetary boundary layer height and structure by Raman lidar: comparison of different approaches, Atmos. Meas. Tech. Discuss., 6, 5195-5216, doi:10.5194/amtd-6-51952013, 2013.

Szintai, B.: Improving the turbulence coupling between high resolution numerical weather prediction models and Lagrangian particle dispersion models, Ph.D. thesis, Swiss Federal Institute of Technology, Zürich, Switzerland, 2010.

Wang, Z., Cao, X., Zhang, L., Notholt, J., Zhou, B., Liu, R., and Zhang, B.: Lidar measurement of planetary boundary layer height and comparison with microwave profiling radiometer observation, Atmos. Meas. Tech., 5, 1965-1972, doi:10.5194/amt5-1965-2012, 2012.

White, A. B., Fairrall, C. W., and Wolfe, D. E.: Use of $915-\mathrm{mHz}$ wind profiler data to describe the diurnal variability of the mixed layer, AMS, in : Proc 7th Joint Conf. Appli. Poll. Meteor., AMS, 14-18 January, New Orleans, LA, J161-J166, 1991.

Zahng, N., Chen, Y., and Zhao, W.: Lidar and microwave radiometer observations of planetary boundary layer structure under light wind weather, J. Appl. Rem. Sensing, 6, 063513-1-063513-8, doi:10.1117/1.JRS.6.063513, 2012. 